\title{
The role of district energy in greening existing neighborhoods: a primer for policy makers and local government officials
}

\author{
T. Osdoba ${ }^{1}$, E. Dunn ${ }^{2}$, H. Van Hemert ${ }^{1}$ \& J. Love ${ }^{1}$ \\ ${ }^{I}$ Center for Sustainable Business Practices, University of Oregon \\ Eugene, Oregon, USA \\ ${ }^{2}$ Preservation Green Lab, National Trust for Historic Preservation, \\ Seattle, Washington, USA
}

\begin{abstract}
District energy systems will play an ever more critical role in achieving community sustainability goals, as standards for energy efficiency and GHG emissions get more aggressive, and as existing buildings hit the limit of what can be accomplished within their property boundaries. District energy systems, especially those based on renewable fuels and/or the capture of waste heat, offer a very low-cost and low-carbon alternative for providing heat, hot water and cooling to entire communities of homes and businesses. Such systems are relevant and viable in both traditional urban villages and compact rural towns. The coordination required among multiple owners for the financing, build-out and connection to such systems poses challenges that local governments need to be poised to solve. At the same time, the "utility service model" that often emerges as the basis for solutions can also be used to organize and fund other community-based energy and infrastructure projects, ranging from water management to complete streets to urban agriculture. The Preservation Green Lab has collaborated with the University of Oregon's Lundquist College Center for Sustainable Business Practices to create a policy primer and roadmap for communities wishing to create or expand district energy systems in neighborhoods of older and historic buildings.

Keywords: district energy, renewable energy, eco-district, district heating, district cooling, combined heat and power, municipal energy policy.
\end{abstract}




\section{Introduction}

As cities look for innovative means of reducing carbon emissions from the operation of their existing buildings, it is increasingly clear that the most effective way to achieve high levels of energy performance rests with districtlevel approaches to the built environment. This paper explores the vital role that low-carbon district energy systems (i.e., neighborhood-scale utilities that deliver thermal energy for heating, cooling, and hot water) can play in enabling existing buildings and established urban neighborhoods to meet aggressive emission reduction targets in a cost-effective way. It also highlights the essential role local governments must play in supporting the development of district energy systems, and is intended as a primer for communities that are beginning to look at district energy as a possible strategy for reducing their emissions and dependence on non-renewable energy sources. Many communities face common barriers, capacity constraints, and learning curves, and this publication identifies the policies and programs needed to foster district energy system development.

\section{The trend toward district-level action}

Many communities that are pursuing aggressive policies to measure and improve the energy performance of their existing building stock are starting to experience the limits of an approach that focuses on individual buildings. Each existing building presents a unique set of challenges and opportunities, defined to some extent by its original size and design. Many existing buildings, especially those that make up our "urban villages" and our small town "main streets," are too small in scale or were designed in such a way that they cannot take advantage of some of the dramatic energy efficiency features or on-site renewable energy options available to new construction. Also, individual buildings are unable to tap into many cleaner sources for thermal energy; an investment in a waste heat recovery system or a biomass facility, for instance, is usually going to be impossible for a single building, and becomes an option only when a central facility is designed to harvest that energy for use by many buildings.

Issues such as these are encouraging some cities to expand their sustainability efforts to a district level, focusing on community-wide energy performance metrics and policies that enable building owners to combine their demand for greener energy and to share sustainable infrastructure across property boundaries. This also represents a shift from citywide policies and infrastructure efforts down to a more manageable scale, that of a neighborhood or district. This reorientation to "eco-districts" has become a catalyst for innovation and experimentation, and has begun to unlock a number of practical solutions related to key urban sustainability priorities - including not just thermal energy but also power generation, storm water management, waste water reclamation, and urban agriculture. 


\section{About district energy}

District energy is not a new idea - many cities developed central heating systems in the early 1900s. However the benefits of district energy were overlooked during the latter half of the 20th century, when energy and land were cheap, and development was sprawling rather than compact. Now communities are rediscovering the potential of district energy systems in light of the current era of urbanization, energy insecurity, and climate change mitigation.

In general terms, district energy systems provide for the heating and hot water needs of a community of buildings, which are connected through a thermal network of pipes under the streets that carry hot water from a centralized energy plant. District energy can also provide cooling services, through the use of a similar piping infrastructure with chilled water. The thermal energy required can be generated from a diverse range of sources, including natural gas boilers, ground-source heat pumps, combustion plants that burn wood or other forms of biomass, and sources of waste heat that can be captured from power plants, industrial facilities, sewers, and waste water plants.

District energy systems are local, neighborhood utilities. They are specifically created to deliver heating and cooling services to the buildings in a defined service area, to finance construction (plant, piping, and building connections), and to charge end users for those services. The financing and build-out of new systems in neighborhoods of existing and historic buildings requires substantial coordination among multiple owners. This coordination effort requires the leadership of local governments, as they have unique and essential capabilities to enable district energy system development.

\section{Benefits of district energy}

District energy systems help cities to achieve their economic, environmental, and social objectives related to buildings and development, and provide long-term, efficient, and affordable energy to their building customers.

\subsection{Key benefits to communities}

District energy provides a platform for cities to increase efficiency, reduce greenhouse gas emissions, and adopt new technologies and fuel sources over time. Given the advantages achieved through diversification of peak load times and 'right-sizing' of equipment for aggregate loads, district energy systems can produce significant efficiency gains. District energy systems also provide opportunities for shifting to cleaner energy sources over time and for capturing available forms of waste energy (from industry, for example, or sewer systems) that individual buildings cannot get access to or justify the capital investment needed to do so.

A district-wide system simplifies such transitions, since installing or upgrading a central generation plant to cleaner technology can deal with an entire community. St. Paul, Minnesota, for example, was able to convert its system 
from coal and natural gas to waste wood as a primary energy source, dramatically reducing emissions for the existing buildings connected to the system [1]. The combined effect of greater system-wide efficiency and access to cleaner energy generation made possible by district energy means that emissions reductions can be significantly higher than could be realistically achieved on a building-by-building basis. It is estimated that Vancouver's Southeast False Creek project achieved about a 70 percent reduction in greenhouse gas emissions compared to a business-as-usual scenario, with the reduction equally split between the improved efficiency (one plant serving multiple buildings) and cleaner fuel/technology choice (in this case sewer heat recovery) [2].

District energy opens up new sources of capital for improving performance of a community's existing building stock. As with other types of utilities, the revenue stream from the aggregation of customers paying for heating, cooling, and hot water systems enables access to capital, such as municipal bonds and/or state and federal grants, or even private project finance investors, that is usually unavailable to individual building owners. A city can create new tools to finance energy performance improvements to entire neighborhoods in one phase of work. This local utility approach to energy system development also gives communities the option, should they want it, of taking greater ownership of local infrastructure assets and providing long-term operating revenues back to the community. In any case, the system owner, whether a community-based or a privately-owned utility, can leverage long-term financing to cover the upfront capital costs with a rate structure that pays off the financing over time.

District energy provides a platform for managing energy costs over the long term. Aggregate demand for fuel, whether from natural gas, biomass or other sources, allows communities with district energy systems to negotiate long-term contracts for portions of their fuel costs, thereby moderating cost variability. St. Paul's system was a response to concerns of building owners about long-term energy prices [1]. Also, once a district energy service model for heating or cooling is established in a community, the aggregation of customers makes it easier for a community to negotiate such things as bulk installation of on-site equipment, such as solar panels, or bulk purchases of green power from remote sources through a utility contract.

District energy helps mitigate long-term risks. District energy systems can reduce risk for cities in terms of future energy and environmental policy, carbon costs, fuel availability and cost variability, and the future effects of climate change. For example:

- Toronto's investment in district cooling enabled the city to meet its Montreal Protocol obligations by reducing refrigerant use in individual buildings [3].

- In Nashville, significant upgrades to an established system were supported by the city in order to reduce risk from air quality violations [4].

Given the risks to owners posed by climate change regulation and energy prices, cities may also consider district energy as a way to "future-proof" their property tax base by protecting owners against future energy price and/or policy 
shocks. District energy can also serve to mitigate the risks and challenges associated with relying on our late 20th-Century model of big infrastructure, which includes the vulnerability of large systems to regional-scale failures, especially in areas prone to natural disasters (i.e., earthquakes, volcanoes). District-level thermal energy and CHP plants can create badly-needed redundancy of supply, and mitigate the impact of disasters, making communities more resilient.

District energy can help communities respond to broader environmental goals and advance their other district-level environmental services. In Vancouver, a community vision for carbon neutrality was the determining factor in bringing district energy into reality [2]. Some communities want to reduce the "out of sight out of mind" effect and let people know more about where their energy comes from, instead of having smoke stacks and plants hidden far outside the city limits. Others are trying to "right-size" systems for energy and other services as a response to the limits of both large regional infrastructure and of individual buildings, and then trying to find synergies between different types of infrastructure and resources as they move to more environmentally friendly solutions.

More commonplace in the near term, however, may be cases like West Union, Iowa, where a pragmatic analysis of return on investment prevailed. After receiving federal and state funds to improve energy efficiency and implement a "Complete Streets" design that provides greater amenities for pedestrian, cycling, and transit users, and doing an energy audit of their existing and historic building stock, community leaders decided that selected retrofit measures combined with a new district energy system will optimize the community's return (both economic and environmental) on the total sum of available private and public funds [5].

\subsection{Key benefits to building owners}

Making sure that energy consumers and building owners understand the ways that district energy directly benefits them is critical. Of course many of these benefits overlap with those of communities - what's good for owners is good for communities, and vice versa. Nevertheless, in order to engage the participation of owners and tenants, cities need to analyze and articulate how district energy benefits them through cost savings and increased energy efficiency over the long term.

District energy offers energy cost savings and price stability. The bottom line for any building owner is cost. Long-term net cost savings are a key selling point of district energy systems. District energy delivers lower cost energy through improved efficiency, load diversification, and economies of scale. Also due to the long-term aggregate nature of demand, a district energy system operator can negotiate long-term fuel contracts, which facilitates greater energy price stability for consumers.

District energy responds to market and regulatory demand for higher energy performance. Buyers and renters are becoming more and more aware of the energy performance of existing buildings which makes energy efficiency a 
source of either opportunity or risk for owners, depending on how well their buildings compete. Cities are now adopting new policy initiatives around energy performance ratings and disclosure to accelerate the degree to which market forces will distinguish efficient buildings from those that use too much energy. Some cities, like Seattle and Vancouver, are already moving beyond disclosure policies toward regulations that will require buildings to meet aggressive postretrofit energy targets in return for flexibility to innovate in how they achieve such targets, including use of on-site renewable generation equipment and/or low-carbon district energy sources. District energy offers an essential opportunity to owners in this emerging policy environment.

District energy relieves building owners of responsibility for delivery and management of heating, cooling, and hot water. With district energy, building owners receive reliable and predictable energy service from professional system operators. This means fewer worries for building management staff, in terms of fuel price uncertainty and system maintenance, upgrade and repair, compared to on-site systems.

District energy relieves building owners of responsibility for delivery and management of heating, cooling, and hot water. With district energy, building owners receive reliable and predictable energy service from professional system operators. This means fewer worries for building management staff, in terms of fuel price uncertainty and system maintenance, upgrade and repair, compared to on-site systems.

District energy offers owners a platform to upgrade fuels and technology. District energy allows cities and building owners to "fuel switch" over time to take advantage of new clean energy technology options and access capital financing for these fuel/technology upgrades. District energy improves air quality. The hydronic heating and cooling systems that are often used with district energy produce less dust and airborne contaminants than forced air systems, and provide far more even and comfortable heat than electric resistance options. Many upscale residential buildings offer hydronic heating as an amenity.

District energy enables incentives and financing that would not otherwise be available. District energy systems can attract sources of financing, such as municipal bonds or community energy grants, which are not available to individual owners. The cost efficiencies gained with district energy utility can in some cases create enough of a revenue premium for cities to offer incentives to owners of existing buildings for installing systems compatible with district energy and connecting to the system. This in turn can enable owners to take into consideration the full spectrum of options for replacement of heating and cooling equipment without having to bear a first cost premium.

\section{Synopsis of key findings}

\subsection{Changing scale of opportunity, policy, and investment}

Efforts to reduce future regulatory risk and achieve community energy performance goals are likely to be key drivers of district energy systems. In 
neighborhoods of existing and historic buildings, the desire to optimize the use of public and private funds targeted to energy retrofits will be a further motive. An individual building can only accomplish so much on its own with regard to performance, whether related to energy, or water, or even social goals. While some new buildings have achieved "net zero" operating performance (e.g., they produce as much energy as they consume over the course of a year), achieving this performance requires a significant cost premium upfront, and this cost premium is likely to be more significant for existing buildings where the ability to integrate renewable energy equipment can be limited based on the building's size and design. A building-centric approach may miss opportunities to share equipment across buildings and to spread those costs over many buildings.

To illustrate these points, consider what steps a building owner in an existing building must take to reduce greenhouse gas emissions to very low levels (i.e., 80 percent or more below current levels). Conventional technologies - the use of insulation, weather-stripping, and other weatherization measures - can usually reduce energy usage by 50 percent at best. Further reductions in greenhouse gas reductions require the transition to cleaner sources of fuel. Without a districtoriented approach, every building currently using natural gas boilers for heating would need to identify and switch to a source of energy with lower greenhouse gas emissions. Such an undertaking would be expensive and take considerable time, since each building owner has already invested in his or her heating equipment and the lifecycle of those investments vary.

Aware of these constraints, many cities are re-examining how upfront investments toward building energy performance can be spent to yield the best overall return on investment (in terms of both dollars and climate change mitigation), given the duplication of equipment, energy load, square footage loss, and sheer effort of taking the building-by-building approach. National organizations have responded to this opportunity with newly proposed legislation at the federal level that proposes to extend the energy production tax credits for power generation to generation of thermal energy.

\subsection{Cities play a critical role in district energy development}

District energy can help cities improve the performance of their neighborhoods, and deliver value to building owners by improving energy efficiency and developing clean, renewable forms of energy for the heating, hot water, and cooling needs for buildings. However the successful implementation of district energy can be challenging, especially in neighborhoods of existing buildings with multiple private owners. The need to invest time and political capital, and possibly public resources, in district energy is not based on expediency-the benefits are less than tangible, hard to link directly to the average citizen, and are often not visible in the short term. Many times, an institutional disconnect between cities and developers/building owners means that they cannot justify making long-term investments, nor do they have easy access to financing that can accommodate the longer-term economic payback.

Cities have a unique and essential role to play, first in establishing a neighborhood-scale utility model, which allows communities to make different 
decisions about capital investments, risk management, and technologies than individual building owners or large utilities could. Once this model is established, cities can then play a direct role in attracting financing. Successful district energy projects have used city bonds as part or all of the significant capital financing needs. Both Nashville and Toronto used revenue and general obligation bonds in tandem to raise the necessary capital for infrastructure and energy plant construction $[3,4]$. The use of municipal bonds can be an important factor for decisions by federal, state, and private investors, who look to municipal support as a key indicator of city priority and capacity for fostering district energy.

In addition to providing upfront financing, cities are in a unique position to facilitate system development when they make other key infrastructure improvements, such as replacing sewers or water pipes. Given the large capital cost of pipes to distribute hot or cold water throughout the planned service area, installing those pipes in tandem with other construction work can save significant amounts of money, and ensures the district energy system will be cost-effective to building owners. These opportunities not only help reduce costs significantly, but also create momentum for the system to expand over time.

Local jurisdictions (depending on specific structure and authority) can also set policies to help level the playing field for profitable district energy development. They can regulate building energy performance policy and exercise land-use controls to regulate/incent connections to district energy systems. Some cities won't have the political will and/or financing capabilities to develop systems, but may have other tools to encourage development of systems by others and to secure a strong customer base and sufficient energy load to make private capital investments less risky.

\section{Policy road map}

Every city presents unique challenges, however the following are common critical elements to a district energy plan. In established neighborhoods, where change can evolve quite slowly, cities can preserve future opportunities by preparing now.

\subsection{Create tailored community energy policies}

Community energy policies should reflect local opportunities, respond to future regulatory risks, and incorporate long-term objectives for efficiency and clean energy generation consistent with higher-level goals for climate change action and economic resilience. Citywide or regional targets for demand reduction and clean energy generation will provide the needed impetus for identifying potential districts and recognizing catalysts. Building-level policies will ensure that owners improve structures in a manner that is compatible with district energy, such that over the course of several years a community can accumulate enough buildings in close enough proximity to connect them with piping infrastructure to shared energy plants. 


\subsection{Identify target areas that have a high probability of success}

Existing neighborhoods must have sufficient density to ensure adequate demand and a mix of uses that allows for load diversification. A majority of existing buildings within close proximity must have heating, cooling, and hot water systems that are compatible with district energy. Target areas should have ready access to local, clean sources of energy, such as sewers or waste water plants, waste heat from industrial processes or biomass. Coordinating with infrastructure projects to upgrade sewer or water lines, install rail transit, or improve streets can help reduce civil engineering and construction costs.

\subsection{Recognize and respond to catalysts}

A number of catalysts can provide the impetus for developing a district energy system. Catalysts can come in many forms, ranging from energy policy changes, new financing sources, changes in technology, new infrastructure projects, or grassroots community efforts.

\subsection{Build institutional capacity}

District energy systems are challenging to develop, and a city interested in fostering their development needs to prepare for and maintain a commitment of staff time and policy focus. In some cases, cities must be prepared to exercise rate setting authority in order to capture customers and secure better financing terms. In other cases, cities need to be prepared to lead by example by being their own energy customer.

\subsection{Secure the customer base}

District energy systems are only viable with a customer base of building owners who are focused on their long-term energy needs and who understand the utility service being provided. Cities must first work with existing building owners to make their buildings compatible, and in some cases, to offer owners a "turn-key" energy service model, in which the city assumes responsibility for heating and cooling equipment in individual buildings until such time as system construction becomes viable.

\subsection{Take steps to manage construction, financing and policy risks}

Connection to district energy should reduce risks for building owners and communities. Building owners need to be assured that connecting to a district energy system will increase their energy independence and decrease their exposure to system failures. During the initial stages of system development, a city and other key stakeholders (business representatives, energy advocates, customers) need to systematically identify and address risks associated with financing the construction of the system. Cities have a direct role to play in this respect, and while the current fiscal situation may make public sector investment seem unlikely, such investment can often represent a key to success. 


\section{Conclusions}

Energy policies are changing dramatically. Driving forces include climate change, a desire for less reliance on fossil fuels (especially imports from unstable countries), and strong economic benefits that can come with greater energy efficiency and widespread deployment of clean, renewable energy technologies. In the future, the use of energy that contributes to greenhouse gas emissions will become increasingly expensive. Buildings that rely on these energy sources face higher energy costs, and will be well served by greatly improving their efficiency and finding cleaner forms of energy. However, investments in building efficiency and cleaner forms of energy will be financed less by individual building owners and more by new finance models that leverage capital from public and private sources that are interested in the returns available from clean energy systems.

A shift in scale from individual buildings to neighborhood districts is essential to helping to reduce the costs that regulation and more expensive energy will impose on building owners and occupants, and to creating the opportunity to use financing strategies that can make investments in improved community-wide performance. District energy is emerging as an important element of our future energy system because it creates a platform for migrating entire communities of existing buildings to systems that use less energy and can tap into cleaner forms of energy over time, all at lower cost than would be possible for individual buildings. This neighborhood-scale approach applies to a range of urban infrastructure services and resources, from urban food production and water treatment to smart grid technologies. The owner cooperation, aggregation of demand, and service model established for district energy can also serve as the foundation for these other "eco-district" services and projects.

City leadership is central to district energy; the potential for district energy cannot be exploited without the engagement of city government. Our cities will set the policies that affect how buildings use energy, create plans that can identify the best opportunities to foster new district energy systems, create the institutional context in which district energy systems can be created, and provide the ongoing attention to energy that individual building owners cannot do on their own. To do so effectively, cities need to understand how district energy works and how to foster district energy development.

District energy requires holistic thinking about neighborhoods, with clear policy approaches that support the collaboration of building owners, utilities, and government to achieve efficiencies and reduce energy use and greenhouse gas emissions on a larger scale. The more a city can integrate district energy into its long-term plans and strategic objectives, the better the likelihood that systems can be integrated into existing neighborhoods when opportunities present themselves. 


\section{References}

[1] Rydaker, Anders. President, District Energy St. Paul. Personal Interview by Jaxon Love. 22 Jan 2010.

[2] Baber, Chris. Neighborhood Energy Utility Project Manager, City of Vancouver. Personal Interview by Tom Osdoba. 25 Jan 2010.

[3] Soumalias, Yianni. Regulatory Affairs Advisor, Enwave Energy Corporation. Personal Interview by Hendrik Van Hemert. 08 Feb 2010.

[4] Bradley, Michael. Office of Finance, Metro Nashville. Personal Interview by Hendrik Van Hemert. 28 Jan 2010.

[5] Geerts, Jeff. Special Projects Manager, Iowa Department of Economic Development. Personal Interview by Tom Osdoba. 23 Sep 2010. 